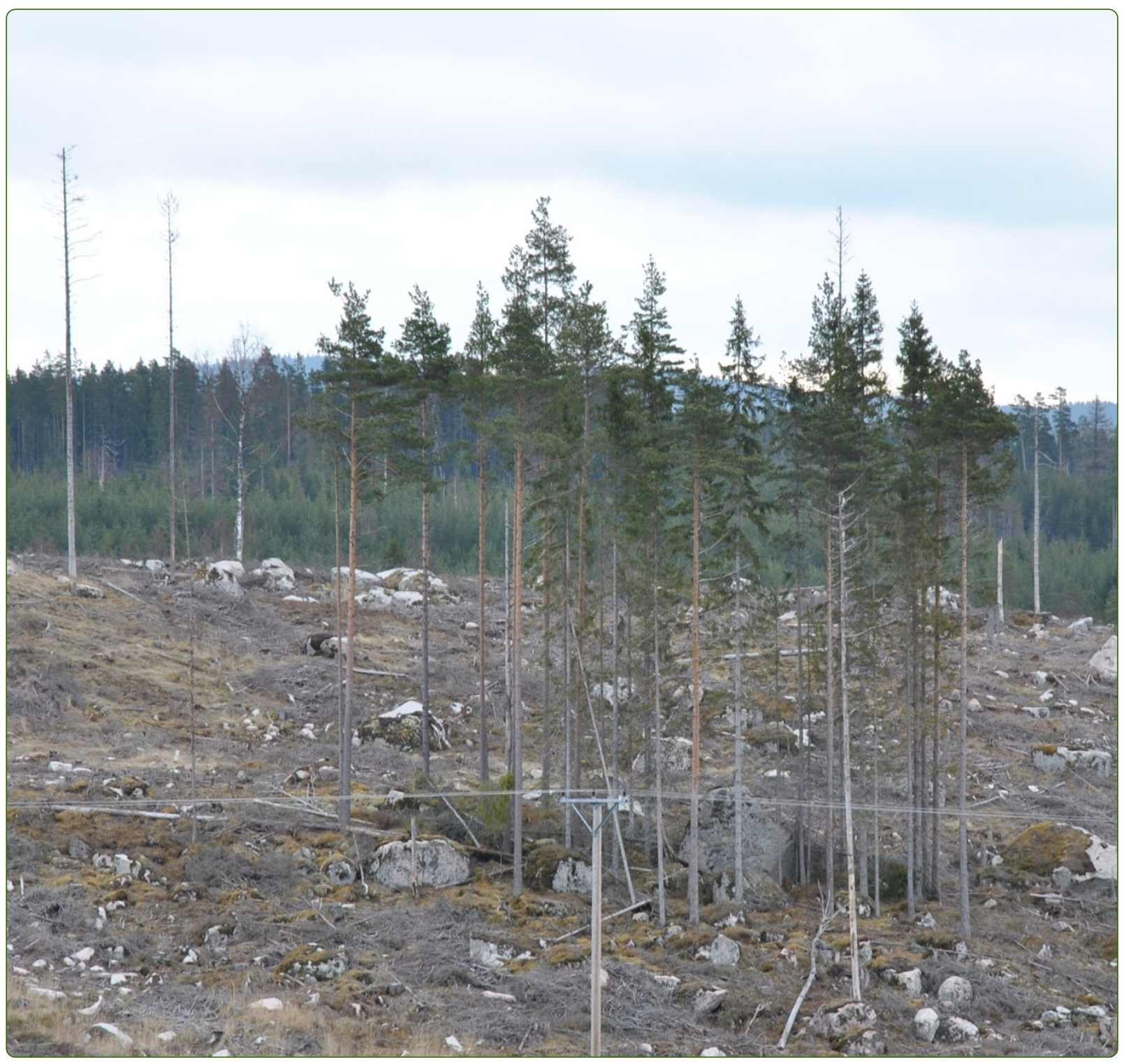

Does the amount of trees retained at clearfelling of temperate and boreal forests influence biodiversity response?

Fedrowitz and Gustafsson 


\title{
Does the amount of trees retained at clearfelling of temperate and boreal forests influence biodiversity response?
}

Katja Fedrowitz ${ }^{*}$ and Lena Gustafsson

\begin{abstract}
Clear-felling is one of the main methods used in many parts of the world for the production of pulp, timber and bioenergy, leading to a simplified forest structure and species composition. One of the measures to mitigate the impact of logging on biodiversity is the retention of trees at final harvest. Tree retention approaches in forestry are still rather new, although widely distributed across different continents. Several studies have been performed on the effects of retention trees on biodiversity but to date there is no evidence on the relation between the amounts of trees, i.e. the number, volume or area per ha retained, and the response of biodiversity.

The overall aim of our review will be to provide forest practitioners and conservationists in temperate and boreal forests with more detailed recommendations regarding the amount of trees that should be retained in order to achieve positive effects for biodiversity compared to traditional clear-cutting.
\end{abstract}

Keywords: Green tree retention, Biological legacy, Veteran tree, Remnant tree, Residual tree, Retention threshold, Clear-cut, Logging, Species composition, Species richness, Extinction risk

\section{Background}

Intensive forestry has modified forest landscapes worldwide, with a decrease in global forest extent (habitat loss) and an increase in habitat fragmentation, resulting in negative effects for biodiversity [1,2].

Industrial forestry is common in different parts of the world, with more or less intense forest management and harvest for the purpose of producing pulp, timber and bioenergy. Clear-cutting is a traditional method of logging, i.e. the complete removal of the tree layer and a subsequent regeneration of even-aged stands. This practice has been controversial due to the simplification of forest structure and composition [3], and the type and intensity of disturbance that occur under industrial forestry can deviate dramatically from natural disturbance processes [4]. The resulting lack of complexity in managed stands and across forest landscapes feeds back on ecosystem processes and carries high risks of reducing several key environmental services [e.g. 5].

\footnotetext{
*Correspondence: katja.fedrowitz@slu.se

Department of Ecology, Swedish University of Agricultural Sciences (SLU), P.O. Box 7044, SE-750 07 Uppsala, Sweden
}

A new forest management model - "retention forestry" was introduced in northwestern North America about 25 years ago as a response to the rapid ongoing transformation and simplification of forests, and the need to create greater balance between wood production and biodiversity [6]. Retention forestry spread rapidly and was adapted to conditions in various regions of the world [7]. Prescriptions can vary in a multitude of ways with large variation in type, amount, and spatial distribution of retained trees to achieve different ecological outcomes. The primary goal is to provide for continuity in ecosystem structure, function, and composition between forest generations. Legacies, such as large old trees and dead trees, are structural elements that take a long time to develop and are therefore rare in intensively managed forests, where trees are comparatively young when they reach economic maturity. For species and populations, the retention approach facilitates the maintenance of habitat for epiphytic plants, woodinhabiting insects and fungi, and many other organisms [reviews in 8,9]. Thus retention provides lifeboating [10] of forest interior species through the regeneration phase of forest development. By improving connectivity of habitats within the managed landscape,

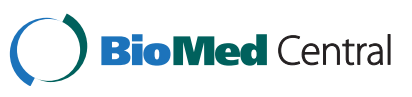


re-colonization and dispersal of organisms are enhanced in harvested compartments [e.g. 10,11]. The maintenance of ecosystem function is another fundamental role of the retention approach. Finally, tree retention has the function to promote species related to natural disturbance and early-successional species [9].

There is a large amount of research studies on ecological effects of retention forestry. Two reviews summarize ecological responses, one on green-tree retention in Europe and North America [8], and the other on living as well as dead trees in northern Europe [9]. Several large long-term experiments have been established [e.g. 12,13]. Despite these research efforts, there is a lack of knowledge on the link between the amount of retained trees and the biodiversity response, e.g. if there are thresholds in numbers of trees retained per ha, volume per ha, area per ha, or proportion of original trees per ha for response. It is of major interest to practical forestry as well as conservation to know to what extent the amount of trees retained at final harvest influences biodiversity, and thus deeper insights into the specific aspect of amounts retained are needed. The overall goal of this review is to provide forest practitioners and conservationists with more detailed recommendations regarding the amount of live and dead trees that should be retained in temperate and boreal forests to achieve positive effects for biodiversity compared to traditional clear-cutting.

\section{Objective of the review Primary question}

Does the amount of trees retained at clearfelling influence biodiversity response?

We use the term 'biodiversity' as a proxy for terrestrial species diversity, and exclude genetic and ecosystem diversity.

The following components are contained in the question:

Population: terrestrial biodiversity at clearfell-sites in temperate and boreal forests

Intervention: trees retained at clearfelling after final harvest, including different amounts of retained trees per ha in trees/ha, volume/ha, proportion of original trees/ha or area/ha as well as single trees versus tree groups

Comparator: before/after clearfelling; uncut forests compared with retention; clearfell with/ without retention

Outcome: effects on terrestrial biodiversity after clearfell with tree retention, including changes in species composition, abundance, diversity or richness and effects for species survival

\section{Secondary questions:}

The following secondary questions will be considered in the data synthesis and presentation:

- Does biodiversity response vary with climatic region, forest type or organism groups?

- Which effects on biodiversity are likely at the levels practiced today, with respect to different regions?

- Are there thresholds for retention amounts that have to be reached for a positive response of biodiversity, i.e. to life-boat and to support forest interior species as well as disturbance prone and early succession species?

- Are there differences between dispersed and aggregated retention, and does the size of retention groups matter?

\section{Methods}

The review team and stakeholder group for this review is formed by representatives of an international group of researchers most of who participated in a global workshop on tree retention in Sweden in 2011 [7] as well as representatives from a panel of forest practitioners from the Swedish multidisciplinary research program "Smart Tree Retention".

\section{Search strategy}

All searches will be conducted in English. The aim of the search is to obtain an unbiased and comprehensive sample of published literature relevant to the primary research question. Secondary research questions will not be explicitly considered when developing the search strategy but will be taken into account in the data analysis and synthesis after the search has been conducted.

\section{Search terms}

Search terms will be based on the population, intervention, and outcome of the primary question, and search strings will always include the terms relevant to the intervention. For all search terms the field tag, TS, for "topic" (in Web of Science), or TITLE-ABS-KEY (in Scopus), will be used, including searches of the title, abstract and keywords of the article. The wildcard symbol " will be used to include plural terms where applicable, while quotation marks will denote that entire phrases will be searched for. The Boolean operator "OR" will link all terms belonging to the same group, e.g. all terms relevant for the intervention, while the Boolean operator "AND" will link terms of different groups, e.g. terms relevant to the subject with terms relevant to the intervention.

Search terms relevant to the intervention include "retention level", "retention pattern", "retention felling", "biological legacy", legacy, "green tree retention", 
"structural retention", "variable retention", "retention approach", "dispersed retention", "aggregated retention", "group retention", retention tree, retention patch, retention group, retention forest, retention aggregate. Instead of "retention", also "residual", "remnant", or "veteran" will be used in combination with the words tree*, patch", group*, forest" or aggregate*. The following "biodiversity terms' are relevant to the population and outcome: biodiversity, "species richness", "species composition", abundance, extinct", diversity, survival, and vitality.

Several search strings have been tested in a preliminary analysis, with the main results summarized in Table 1. Scoping showed that the combination of all terms relevant to the intervention in combination with the terms relevant to biodiversity gave an excess of articles $(>11,000$ and $>13,000$ articles in Web of Science and Scopus, respectively). The search string was therefore modified in several ways (Table 1):

1. Combining the single search term "biodiversity" in combination with all terms relevant to the intervention

2. Adding the following terms related to clearfelling to the search string: clearfell, clear-fell, clearcut, clear-cut, logging, "forest harvest", "final felling"

3. Adding 'boreal or temperate' to the search string

Adding the following terms related to species (species terms) to the search string also resulted in an excess of articles $(>3,400$ and $>4,000$ articles in Web of Science and Scopus, respectively): animal", plant*, butterfly*, insect*, beetle*, lichen*, moss*, bryophyte*, liverwort", fung", "vascular plant", bird", mammal", reptile", amphibian", snail", "soil fauna", "soil invertebrate"," "soil microfung"* mesofauna, microfauna, "soil macrofauna", "ground layer", "ground flora", "herb layer".
Since some articles may not have used any of our terms related to biodiversity but still report a response of a species connected to clearfelling with retention we also tested a second search string in which the terms relevant for the intervention were combined with the species terms. This resulted in an excess of articles $(>12,000$ and $>24,000$ articles in Web of Science and Scopus, respectively). We therefore modified this second search string as well by one of the following:

1. Adding terms related to clearfelling

2. Adding 'boreal or temperate' to the search string

3. Using terms connected to species life forms instead of species terms: epiphyt", epixylic", saproxylic", wood-dwelling, wood-living, "ground vegetation", "forest floor vegetation", herb", shrub*

\section{Publication database}

We will search the publication databases Web of Science and Scopus. Google Scholar will be searched with a simplified search including the terms retention, forest and biodiversity, and only the first 50 hits will be examined from this search. The Directory of Open Access Journals will be searched with a simplified search including the terms "retention and biodiversity". The retrieved references will be exported into the reference manager Endnote. Duplicates will be removed prior to further assessment.

\section{Grey literature and supplementary searches}

Additional grey literature will be provided by the stakeholder group. This literature may also include languages other than English.

\section{Article screening}

Relevant articles for the review will be selected in a stepwise procedure based on the inclusion criteria described

Table 1 Scoping results with abbreviated search terms

\begin{tabular}{|c|c|c|c|c|c|c|c|}
\hline \multirow{2}{*}{$\frac{\mathrm{Nr} .}{1 .}$} & \multicolumn{5}{|l|}{ Search string } & \multirow{2}{*}{$\begin{array}{l}\text { Web of Science } \\
>11,000\end{array}$} & \multirow{2}{*}{$\frac{\text { Scopus }}{>13,000}$} \\
\hline & intervention & AND & biodiversity terms & & & & \\
\hline 1.1 & intervention & AND & "biodiversity" & & & 1,416 & 1,443 \\
\hline 1.2 & intervention & AND & biodiversity terms & AND & clearfelling & 852 & 429 \\
\hline 1.3 & intervention & AND & biodiversity terms & AND & temperate or boreal & 709 & 458 \\
\hline 1.4 & intervention & AND & biodiversity terms & AND & species terms & 3,446 & 4,077 \\
\hline 2 & intervention & AND & species terms & & & $>12,000$ & $>24,000$ \\
\hline 2.2 & intervention & AND & species terms & AND & clearfelling & 726 & 481 \\
\hline 2.3 & intervention & AND & species terms & AND & temperate or boreal & 855 & 543 \\
\hline 2.4 & intervention & AND & species life forms & & & 1,875 & 2,044 \\
\hline \multicolumn{6}{|c|}{ Total number of hits combined, excluding bold numbers ( $8^{\text {th }}$ of May 2012 ) } & 4,237 & 3,890 \\
\hline
\end{tabular}

Two main search strings, 1 and 2, were tested and modified (detailed description in Search terms), resulting in final search strings 1.1-1.3 and 2.2-2.4. Hits are given for Web of Science and Scopus with an access of articles indicated by bold numbers. 
in Study inclusion criteria. In the first step, articles will be excluded if their titles are considered to be irrelevant. In the second step, articles that passed the first step will be excluded if their abstracts are considered to be irrelevant. In both steps the procedure will be conservative, i.e. if there is doubt about the relevance of an article it will be retained.

A kappa test will be undertaken before the second step, i.e. the consistency in the interpretation of the selection criteria will be checked and adjusted for by the amount of agreement expected by chance alone $[14,15]$. The kappa statistic will be based on a minimum of $10 \%$ of the articles (up to a maximum of 500 articles) and a score of 0.5 or more will indicate that both reviewers select the articles in a similar way. If the kappa rating is below 0.5 discrepancies in the decision making need to be discussed and adjusted for before the remaining articles will be assessed.

In the third step, all remaining articles will be viewed in full. A list of all articles identified as relevant will be checked by the stakeholder group for potentially missing data sources. In addition, reference lists of the relevant articles will be checked for further sources of interest. Additional data sources can include non peer-reviewed papers, as well as unpublished data.

\section{Study inclusion criteria}

In order to be included, an article needs to fulfil each of the following criteria:

Relevant population(s): terrestrial biodiversity at any forest site that has been or will be clearfelled in temperate and boreal forests

Relevant intervention(s): the retention of one or more trees or tree groups at clearfelling

Relevant comparator(s): before/after clearfelling; uncut forests compared with retention; clearfell with/ without retention

Relevant outcomes: effects on terrestrial biodiversity after clearfell with tree retention, including changes in species composition, diversity, abundance, or richness and effects for species survival

Relevant types of study design: Any primary study that researches biodiversity in relation to tree retention at clearfelled sites. All terrestrial organism groups are included. The term biodiversity is defined as species diversity, with genetic and ecosystem diversity being excluded. Review articles will not be included but their references will be searched for primary studies.

\section{Study quality assessment}

Prior to data extraction (Data extraction strategy) all articles accepted at full text, i.e. those that have passed the three selection steps described in Article screening, will undergo a quality assessment by the reviewers. Consistency in the interpretation of study quality assessment by the two independent reviewers will be evaluated prior to full assessment based on a few sample articles.

We expect studies of four types: experiment, observational study, descriptive study and data simulation/ modelling approaches. Descriptive studies and those dealing exclusively with data modelling or simulation will be excluded from meta-analysis but included in qualitative tabulation and/or narrative synthesis.

Critical appraisal will result in studies being sorted into four categories, based on their quality of evidence (modified from [16]):

Category 1: random or stratified random design of appropriate size for the species studied; well replicated with relevant control/reference (Figure 1c or Figure 1d)

Category 2: appropriate size for the species studied and

- no (or improper) random design, well replicated with relevant control reference

- or

- random design, well replicated with no control reference

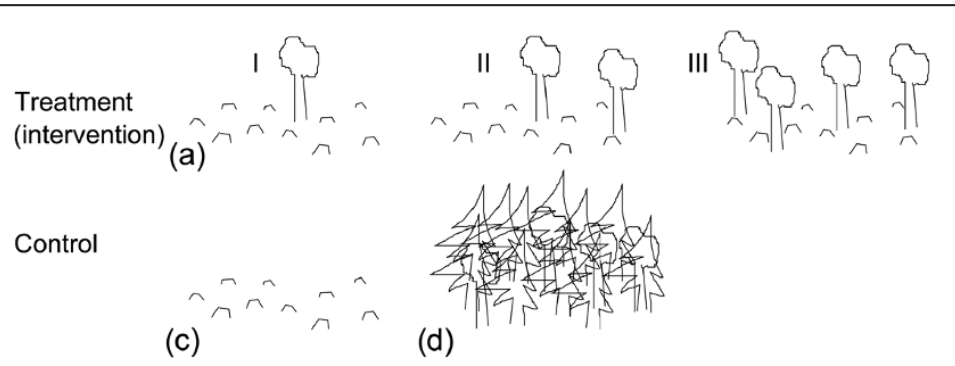

(b)

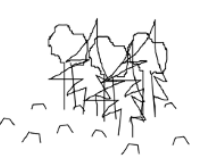
on retention sites with a) single trees or $\mathbf{b}$ ) tree groups. We expect that the amount of retained trees or per ha (a I-III) will differ among studies. Studies that will be included in the meta-analysis need to have a control group which will be either $\mathbf{c}$ ) clearfell sites without retention or d) uncut forests. 
Category 3: opinion based study (e.g. descriptive studies or reports)

Category 4: insufficient evidence due to inadequate study design

Studies with inferior methodology (categories 2-3) will be rejected for meta-analysis, but will be used for narrative synthesis and/or qualitative tabulation. Authors of apparently relevant articles in which extractable data are missing for inclusion in a meta-analysis will be contacted and asked whether these data can be provided. Studies in category 4 will be excluded from the analysis. Lists of studies that were excluded after study quality assessment will be published in an appendix of the review together with the reasons for exclusion.

\section{Data extraction strategy}

A spreadsheet will be used in order to record data from each article. Qualitative and quantitative data will be extracted, and for missing data we will contact the authors of the articles.

The following data will be extracted:

- Article information: title, journal, author, year

- Methodological approach: experimental, observational, descriptive, simulation/modelling

- Geographical location

- Climatic region

- Forest biome: temperate or boreal

- Forest type and forest tree species, e.g. broadleaved, mixed, coniferous

- Forest tree species, e.g. Spruce forest, Pine forest, ...

- Retention tree characteristics: alive/dead, whole trees/stumps, solitary/grouped, tree species

- Amount of retained trees per ha

- Size of the clearcut

- Spatial scale: log, stand, or landscape

- Temporal scale: time after clearcut with retention

- Species studied

- Species life forms studied, e.g. epiphytic, saproxylic, epixylic, wood-dwelling, wood-living, ground vegetation, forest floor vegetation, herb, or shrub

- Additional treatments on the clearcut, e.g. fire or scarification

- Response variable, e.g. species composition, abundance, richness with the respective mean-values, standard deviation and standard error

The exact format and contents of the data extraction will be finalized after study collection (Article screening) since it will depend on the articles included.

\section{Data synthesis and presentation}

We aim to synthesize and present the studies that were reviewed in full in form of narrative synthesis, tables or graphs, with a focus on the different amounts of trees that were retained and on our secondary questions. If possible, a retention threshold will be indicated.

Meta-analysis will be applied for those articles from which relevant information can be extracted or obtained otherwise. Studies will be separated into those that used clearcuts without retention as control group (Figure 1c) and those that used uncut forests as control group (Figure 1d). The potential parameters in the metaanalysis include biodiversity response, such as species richness, diversity, or abundance, as dependent variables, and amount of retained trees, forest biome, time since logging, additional treatments (fire/scarification), retention type, tree variables (alive/dead; tree species), species and species groups and type of retention (dispersed/ aggregated) as independent explanatory variables. With the results of the meta-analysis we aim to show the differences in biodiversity response (eg species richness) between clearcuts, clearcuts with retention, and uncut forests. Further, we aim to analyse if there are differences between different retention levels (amounts of trees retained, dispersed and aggregated retention), between forest biomes, climatic regions, and organism groups.

\section{Competing interests}

No competing interests have been identified. The project is part of the Swedish multidisciplinary research program "Smart Tree Retention" and funded by the Swedish research Council FORMAS.

\section{Author's contributions}

LG conceived of the study, participated in the design and helped to draft the manuscript. KF designed the study and drafted the manuscript. Both authors read and approved the final manuscript.

\section{Acknowledgements}

We thank three anonymous reviewers for critical comments and suggestions that improved the protocol.

Received: 20 March 2012 Accepted: 15 May 2012

Published: 30 May 2012

\section{References}

1. Butchart SHM, Walpole M, Collen B, van Strien A, Scharlemann JPW, Almond REA, Baillie JEM, Bomhard B, Brown C, Bruno J, Carpenter KE, Carr GM, Chanson J, Chenery AM, Csirke J, Davidson NC, Dentener F, Foster M, Galli A, Galloway JN, Genovesi P, Gregory RD, Hockings M, Kapos V, Lamarque J-F, Leverington F, Loh J, McGeoch MA, McRae L, Minasyan A, Morcillo MH, Oldfield TEE, Pauly D, Quader S, Revenga C, Sauer JR, Skolnik B, Spear D, Stanwell-Smith D, Stuart SN, Symes A, Tierney M, Tyrrell TD, Vié J-C, Watson R: Global Biodiversity: Indicators of Recent Declines. Science 2010, 328:1164-1168.

2. Fahrig L: Effects of Habitat Fragmentation on Biodiversity. Annu Rev Ecol Evol Syst 2003, 34:487-515.

3. Puettmann KJ, Coates KD, Messier C: A critique of silviculture: Managing for complexity: Island Press; 2009.

4. Lindenmayer DB, Franklin JF: Conserving forest biodiversity: A comprehensive multiscaled approach.: Island Press; 2002.

5. Thompson ID, Okabe K, Tylianakis JM, Kumar P, Brockerhoff EG, Schellhorn NA, Parrotta JA, Nasi R: Forest Biodiversity and the Delivery of Ecosystem Goods and Services: Translating Science into Policy. Bioscience 2011, 61:972-981.

6. Franklin JF: Towards a new forestry. Am For 1989, 95:37-44. 
7. Gustafsson L, Baker SC, Bauhus J, Beese WJ, Brodie A, Kouki J, Lindenmayer DB, Lõhmus A, Martínez Pastur G, Messier C, Neyland M, Palik B, SverdrupThygeson A, Volney JA, Wayne A, Franklin JF: Retention Forestry to Maintain Multifunctional Forests: a World Perspective. BioScience, 2012, 62:633-645.

8. Rosenvald R, Lõhmus A: For what, when, and where is green-tree retention better than clear-cutting? A review of the biodiversity aspects. Forest Ecol Manage 2008, 255:1-15.

9. Gustafsson L, Kouki J, Sverdrup-Thygeson A: Tree retention as a conservation measure in clear-cut forests of northern Europe: a review of ecological consequences. Scand J For Res 2010, 25:295-308.

10. Franklin JF, Thornburgh DA, Tappeiner JC: Alternative silvicultural approaches to timber harvesting: variable retention types. In Creating a forestry for the 21st century. The science of forest management. Edited by Kohm KA, Franklin JF. Washington, USA: Island Press; 1997:111-139.

11. Chan-McLeod ACA, Moy A: Evaluating Residual Tree Patches as Stepping Stones and Short-Term Refugia for Red-Legged Frogs. J Wildl Manag 2007, 71:1836-1844.

12. Aubry $\mathrm{KB}$, Halpern $\mathrm{CB}$, Peterson $\mathrm{CE}$ : Variable-retention harvests in the Pacific Northwest: A review of short-term findings from the DEMO study. Forest Ecol Manage 2009, 258:398-408.

13. Baker SC, Read S: Variable retention silviculture in Tasmania's wet forests - background and ecological evaluation. Aust For 2011, 74:218-232.

14. Edwards P, Clarke M, DiGuiseppi C, Pratap S, Roberts I, Wentz R: Identification of randomized controlled trials in systematic reviews: accuracy and reliability of screening records. Statistics in Medicine 2002, 21:1635-1640

15. Cohen J: A Coefficient of Agreement for Nominal Scales. Educ Psychol Meas 1960, 20:37-46.

16. Pullin AS, Knight TM: Support for decision making in conservation practice: an evidence-based approach. J Nat Conserv 2003, 11:83-90.

doi:10.1186/2047-2382-1-5

Cite this article as: Fedrowitz and Gustafsson: Does the amount of trees retained at clearfelling of temperate and boreal forests influence biodiversity response?. Environmental Evidence 2012 1:5.

\section{Submit your next manuscript to BioMed Central and take full advantage of:}

- Convenient online submission

- Thorough peer review

- No space constraints or color figure charges

- Immediate publication on acceptance

- Inclusion in PubMed, CAS, Scopus and Google Scholar

- Research which is freely available for redistribution 